\title{
Analysis for Effects of Hearing Aids Performance by Applicability of Hydrophobic Nano-Coating Technique: A Pilot Study
}

\author{
Sung Kyun Kim ${ }^{1}$, Pyung Kon Thak ${ }^{2}$, Bum Yong Choi ${ }^{3}$, \\ Jin Ho Lee ${ }^{3}$, Kyung Soo $\mathrm{Im}^{3}$, and Gi Jung $\mathrm{Im}^{1}$ \\ ${ }^{1}$ Department of Otolaryngology-Head and Neck Surgery, Korea University College of Medicine, Seoul; and \\ ${ }^{2}$ School of Aural Rehabilitation, Woosong University, Daejeon; and ${ }^{3}$ Dongsan Hearing Care Co. Ltd., Seoul, Korea
}

\section{나노방수코팅 기술 적용 여부가 보청기 성능에 미치는 영향에 대한 분석}

김성균 ${ }^{1} \cdot$ 탁평곤 $^{2} \cdot$ 최범용 $^{3} \cdot$ 이진호 $^{3} \cdot$ 임경수 $^{3} \cdot$ 임기정 $^{1}$

고려대학교 의과대학 이비인후-두경부외과학교실, ${ }^{1}$ 우송대학교 청각재활학과, ${ }^{2}$ (주동산보청기 ${ }^{3}$

\author{
Received November 4, 2015 \\ Revised December 17, 2015 \\ Accepted December 21, 2015 \\ Address for correspondence \\ Gi Jung Im, MD, PhD \\ Department of Otolaryngology- \\ Head and Neck Surgery, \\ Korea University \\ College of Medicine, \\ 73 Inchon-ro, Seongbuk-gu, \\ Seoul 02841, Korea \\ Tel +82-2-920-5345 \\ Fax $+82-2-925-5233$ \\ E-mail logopas@korea.ac.kr
}

Background and Objectives Although popular as a method for aural rehabilitation with hearing impairment, hearing aids are susceptible to inflow of foreign materials such as water, sweat, and dust, causing corrosion of the circuit board and eventual device failure. Performance of hearing aids is evaluated by assessing the applicability of hydrophobic nano-coating technique using waterproof hearing aids electronic devices.

Subjects and Method Performance was evaluated using a Fonix 7000 for the maximum output sound pressure level (Max OSPL 90), high frequency average full on gain (HFA FOG), total harmonic distortion and input noise level for 13 hearing aids. Nine of the 13 hearing aids were tested after nano-coating was applied to $2.5 \mu \mathrm{m}$ of thickness. Fro the immersion test, hearing aids were subjected to $1 \mathrm{~m}$ of depth of water and performance was immediately measured; they were also measured after a day and also after a month.

Results In the coated group, Max OSPL 90, HFA FOG were significantly reduced but the corrosion of the circuit board was not observed. The four hearing aids without nano-coating failed to work immediately after the immersion test. However, there were no changes in performance after a month of immersion in any of the aids. For the non-coated group, corrosion of the circuit board was observed after 1 month.

Conclusion Nano-coating is a competitive technology and an advangtage to have to ensure waterproof effect and corrosion prevention. Thus it should be recognized as essential technology to enhance performance of hearing aids.

Korean J Otorhinolaryngol-Head Neck Surg 2016;59(4):281-6

Key Words Coating $\cdot$ Hearing $\cdot$ Hearing aid $\cdot$ Hydrophobic $\cdot$ Rehabilitation.

\section{서 론}

보청기는 소리를 증폭시켜 효과적으로 사람의 귀에 전달 해주는 장치이다. ${ }^{1)}$ 보청기는 감각신경성 난청 환자뿐 아니라 일부 전음성 난청 환자들에게도 적용할 수 있는 치료법 중 하나로, 최근에는 그 수요가 증가하는 추세로, 이에 난청의
조기 진단, 평균 수명 연장으로 인한 고령화 사회로의 진입 등 이 영향을 미치는 것으로 알려져 있다. ${ }^{2)}$

이러한 보청기는 인체와 직접 접촉하는 특성 때문에 착용 중 귀지 및 땀, 이물질의 보청기 내로 들어가거나 높은 습도, 사용 중 실수로 인한 침수 등의 이유로 회로의 부식 및 내· 외부 부품의 손상이 발생할 수 있다. 
특히 보청기의 형태에 따라서 손상 빈도에 차이를 보일 수 있는데 Chang 등히 이 시행한 보청기 수리 경험에 대한 설문 조사에 따르면 귓속형 보청기를 사용하는 환자가 다른 타입 의 보청기를 사용하는 환자보다 통계적으로 유의하게 잦은 수리 경험이 있다고 답했다. 이는 귓속형 보청기의 기계적 특 성도 있을 뿐만 아니라 제한된 외이도 공간 안에서 습기 및 이물질의 배출이 어려운 이유도 보청기 고장의 원인이 될 수 있을 것으로 보인다.

현재, 외부 물질 유입 및 침수를 대비하여, 귀걸이형(behindthe-ear, BTE) 보청기의 경우 Ingress Protection(IP)67등급 (Table 1 and 2)으르로 처리된 보청기가 개발된 상태이지만, 저 자들이 아는 한 아직까지 귓속형(in-the-canal, ITC) 및 고막 형(completely-in-the-canal, CIC), 오픈형(receiver in the canal, RIC)의 경우 방수 기술을 적용한 경우는 아직까지 보고 되지 않았다.

본 연구에서는 제품으로 출시되어 있는 4 가지 유형의 보청 기에 나노방수코팅 기술을 이용하여 코팅 전후 및 침수 후 보 청기 성능을 평가하고, 방수코팅 기술의 유용성 및 적용 가능 여부에 대해 연구하였다.

Table 1. First digit of Ingress Protection grade (solid objects)

\begin{tabular}{cc}
\hline Level & Protection against \\
\hline 0 & No protection against contact and ingress of objects \\
1 & $\begin{array}{c}\text { Solid objects over } 50 \mathrm{~mm} \text {, e.g., accidental touch by } \\
\text { persons hands }\end{array}$ \\
2 & $\begin{array}{c}\text { Protected against solid objects over } 12 \mathrm{~mm} \text {, e.g., } \\
\text { persons fingers }\end{array}$ \\
3 & $\begin{array}{c}\text { Protected against solid objects over } 2.5 \mathrm{~mm} \\
\text { (tools and wires) }\end{array}$ \\
4 & Solid objects over $1 \mathrm{~mm}$ (tools, wires, and small wires) \\
5 & Dust limited ingress (no harmful deposit) \\
6 & Totally protected against dust \\
\hline
\end{tabular}

Table 2. Second digit of Ingress Protection grade (liquids)

\begin{tabular}{cl}
\hline Level & \multicolumn{1}{c}{ Protected against } \\
\hline 0 & Not protected \\
1 & Vertically falling drops of water \\
2 & Direct sprays of water up to $15^{\circ}$ from the vertical \\
3 & Direct sprays of water up to $60^{\circ}$ from the vertical \\
4 & Water sprayed from all directions-limited ingress \\
& permitted \\
5 & Low pressure jets of water from all directions- \\
& limited ingress \\
7 & Temporary flooding of water-limited ingress permitted \\
8 & Long perfect of immersion between $15 \mathrm{~cm}$ and $1 \mathrm{~m}$ \\
&
\end{tabular}

\section{대상 및 방법}

본 연구의 과정은 다음과 같다(Fig. 1). 타입에 따른 보청 기 수는 CIC 타입이 3개, ITC 타입이 3개 BTE 타입이 2개, RIC 타입이 1개였다. 방수 코팅을 위해 나노방수코팅기술 및 장비(HZO 5000; HZO, Salt Lake City, UT, USA)를 보유하 고 있는 업체에 의뢰하였다. 현재 출시되어 있는 BTE, ITC, $\mathrm{CIC}, \mathrm{RIC}$ 타입 보청기 9개에 대해 나노방수코팅 처리 전 보청 기 성능 분석장비(Fonix 7000; Frye, Tigard, OR, USA)를 통 해 최대 포화음압치(maximum output sound pressure level, Max OSPL 90), 고주파 최대출력(high frequency average full on gain, HFA FOG), 전배음 왜곡률(total harmonic distortion, THD), 등가입력 소음치(equivalent input noise level, $\mathrm{Ln}$ )를 측정하였다. 코팅 전 보청기를 분해하여 회로기판 및 마이크, 리시버를 코팅하였고 내부 회로 기판의 변화가 있는 지 확인하였다(Fig. 2A and B). 코팅의 두께는 통상적으로 일반 전자기기에 적용되는 5 8 $\mu \mathrm{m}$ 에 비해, 보청기의 출력 및 성능의 저하를 방지하기 위해 $2.5 \mu \mathrm{m}$ 로 적용하였다.

나노방수코팅 적용 후 같은 보청기 분석장비를 이용하여 보청기 성능을 평가하였으며 나노방수코팅 된 보청기에 대하 여 침수테스트를 실시하였다.

침수테스트는 모든 보청기에 대하여 방수등급 7을 목적으 로 $1 \mathrm{~m}$ 수심에서 40분 동안 침수시킨 후 앞서 언급한 항목 들에 대하여 침수 직후 및 침수 1 일 후 보청기의 성능을 5 회

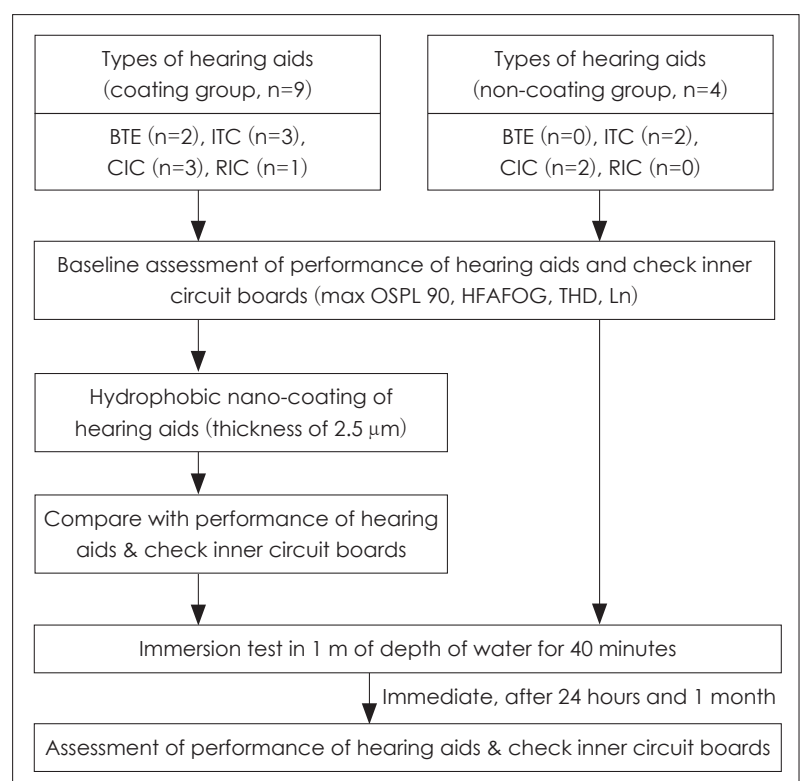

Fig. 1. Flow chart for assessment of a performance of the hearing aids. Max OSPL 90: maximum output sound pressure level, HFA FOG: high frequency average full on gain, THD: total harmonic distortion, Ln: equivalent input noise level, BTE: behind-the-ear, ITC: in-the-canal, CIC: completely-in-the-canal, RIC: receiver in the canal. 

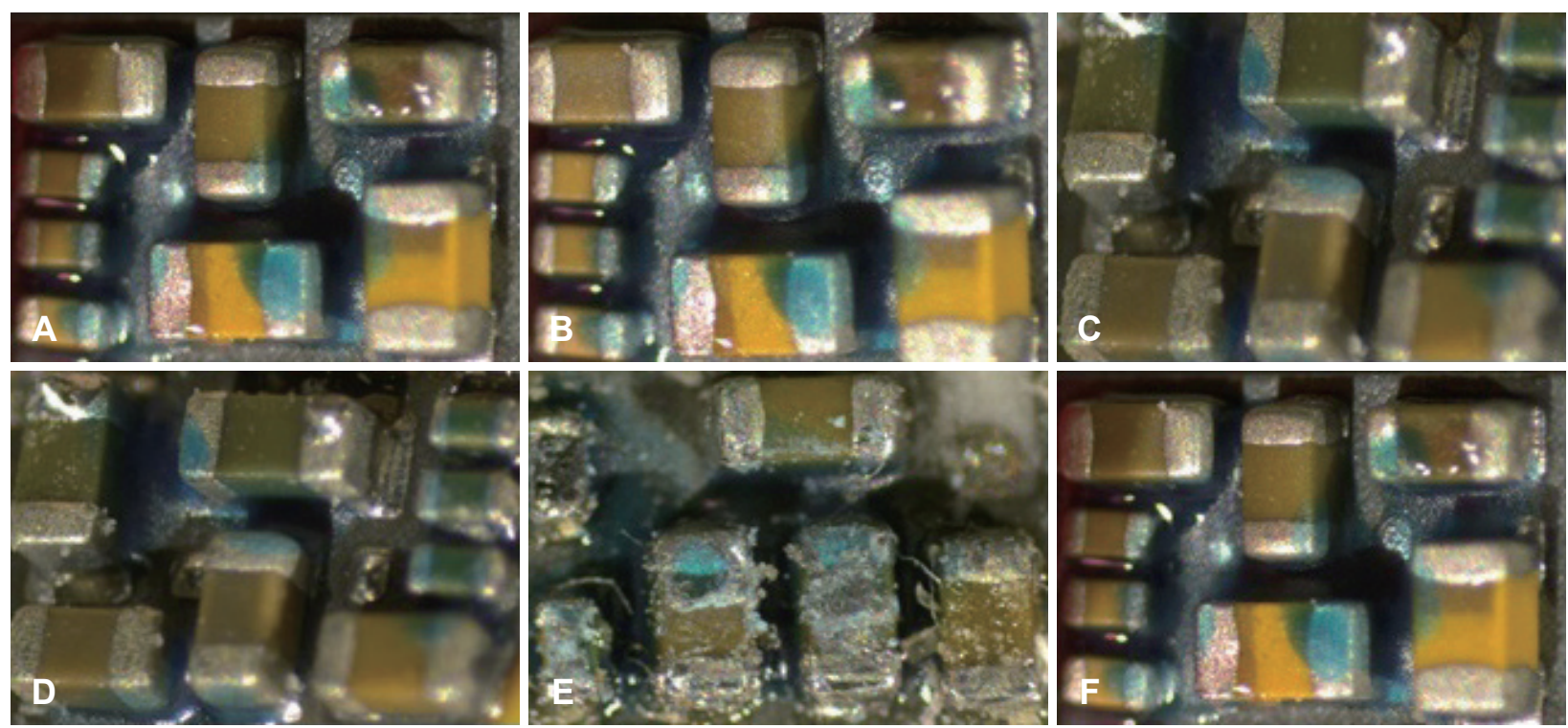

Fig. 2. Circuit board of hearing aids. Circuit board of pre-hydrophobic nano-coating (A). Circuit board of post-hydrophobic nano-coating (B). Circuit board which did not apply for hydrophobic nano-coating after 1 day of waterlogging test (C). Circuit board that apply for hydrophobic nano-coating after 1 day of waterlogging test (D). Circuit board which did not apply for hydrophobic nano-coating after 1 month of waterlogging test. The circuit board showed corrosive spots but there were no functional difference from (C) (E). Circuit board that apply for hydrophobic nano-coating after 1 day of waterlogging test $(F)$.

Fig. 3. Hydrophobic nano-coating device (A). Immersion testing device of hearing aids (B). It was evaluate performance of hearing aids after immersion for 40 minutes in $1 \mathrm{~m}$ of depth of water to meet the IP X7. IP: Ingress Protection.
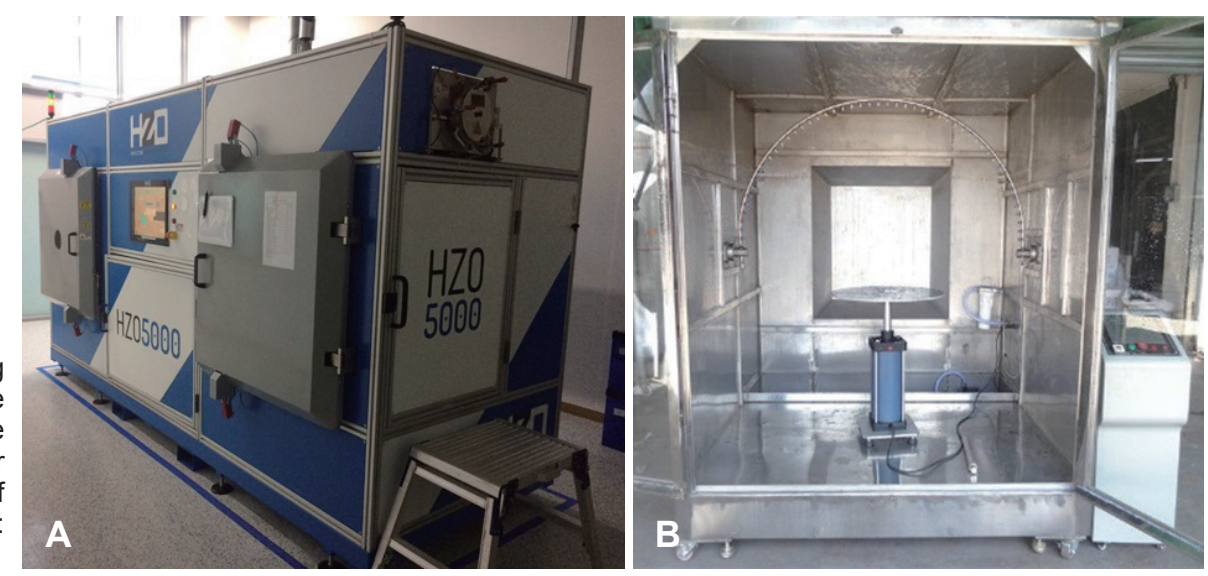

에 걸쳐 동일한 방법으로 테스트하였으며, 내부 회로의 변화 유무를 확인하였다(Figs. 2C, D, and 3).

침수테스트 시 배터리 방전에 의한 영향을 배제하기 위해 배터리를 제거하고 테스트 하였다. 또한 방수 지속성을 확인 하기 위해 침수 1 개월 후 보청기 성능을 평가하였다. 위와 동 일한 방법으로 나노 코팅을 적용하지 않은 ITC 타입 보청기 2 개와 $\mathrm{CIC}$ 타입 보청기 2개에 대하여 침수 실험을 시행하였다.

본 연구에서는 상기 설명한 실험을 같은 조건에서 7회 반복 하였다. 결과 변수에 따른 통계학적 검정은 SPSS 22.0(SPSS Inc., Chicago, IL, USA)을 이용하였다. 조건에 대한 성능 차 이를 분석하기 위하여 결과값에 대한 정규성 검정을 시행 후 정규성을 만족하는 것이 확인되어 paired t-test를 이용하였 다. 통계학적 유의 수준은 $95 \%$ 이상 $(p<0.05)$ 으로 하였다.

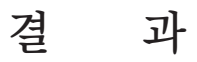

나노방수코팅 처리된 9개의 보청기에 대한 성능을 방수처 리 전의 성능과 비교하였다. 2 개의 $\mathrm{CIC}$ 타입 보청기가 코팅 후 현저한 출력 저하를 보이며 정상적으로 작동되지 않았으 며 성능을 평가할 수 없어 분석대상에서 제외하였다.

Max OSPL 90값은 평균 $4.2 \mathrm{~dB}$ 감소하였으며 $(p<0.05)$, $\mathrm{HFA} \mathrm{FOG}$ 는 평균 $4.9 \mathrm{~dB}$ 감소하였다 $(p<0.05)$ (Fig. 4). 500 $\mathrm{Hz}, 800 \mathrm{~Hz}, 1600 \mathrm{~Hz}$ 에서의 THD는 각각 $0.2 \%, 0.4 \%, 0.7 \%$ 감소하였으며, $\mathrm{Ln}$ 은 평균 $1 \mathrm{~dB}$ 이 감소하였다(Table 3).

침수테스트 직후에 시행한 성능 비교 연구에서는 나노방수 코팅 처리 후와 비교하였을 때 Max OSPL 90값은 침수 전에 비해 평균 $1.0 \mathrm{~dB}$ 감소하였고, $\mathrm{HFA} \mathrm{FOG}$ 는 평균 $0.5 \mathrm{~dB}$ 감 
소하였다.

$500 \mathrm{~Hz}$ 에서의 $\mathrm{THD}$ 는 평균 $0.4 \%$ 증가하였으며 $800 \mathrm{~Hz}$ 는 변화 없었고, $1600 \mathrm{~Hz}$ 는 $0.2 \%$ 증가하였다. $\mathrm{Ln}$ 은 평균 $1.6 \mathrm{~dB}$ 증가하였다(Table 3). 보청기 타입 별로 나노방수코팅 적용에 따른 Max OSPL 90, HFA FOG, THD, Ln 값을 비교하였 을 때 통계적으로 유의한 차이는 없었다.

나노방수코팅을 하지 않은 4개의 보청기를 침수테스트 한 결과 모두 침수 직후에는 작동이 되지 않았다. 24시간 건조 후 침수 전과 비교하여 성능을 측정한 결과 1 개의 ITC 타입
보청기는 작동되지 않아 성능을 평가할 수 없었다.

나머지 3개의 보청기에서 성능을 분석하였을 때 Max OSPL 90값은 변화가 없었고, $\mathrm{HFA} \mathrm{FOG는} \mathrm{평균} 0.5 \mathrm{~dB}$ 증가하였 다. $500 \mathrm{~Hz}$ 에서의 $\mathrm{THD}$ 는 $0.1 \%$ 감소하였으며 $800 \mathrm{~Hz}$ 는 $0.1 \%$ 증가하였고, $1600 \mathrm{~Hz}$ 에서는 변화 없었다. $\mathrm{Ln}$ 은 평균 $0.5 \mathrm{~dB}$ 증가하였다(Table 4).

침수 1 개월 후 나노방수코팅 된 7 개의 보청기와 코팅하지 않은 3 개의 보청기에 대해 같은 방법으로 성능을 평가한 결 과 코팅 유무에 관계없이 모든 보청기가 성능 저하 없는 것으

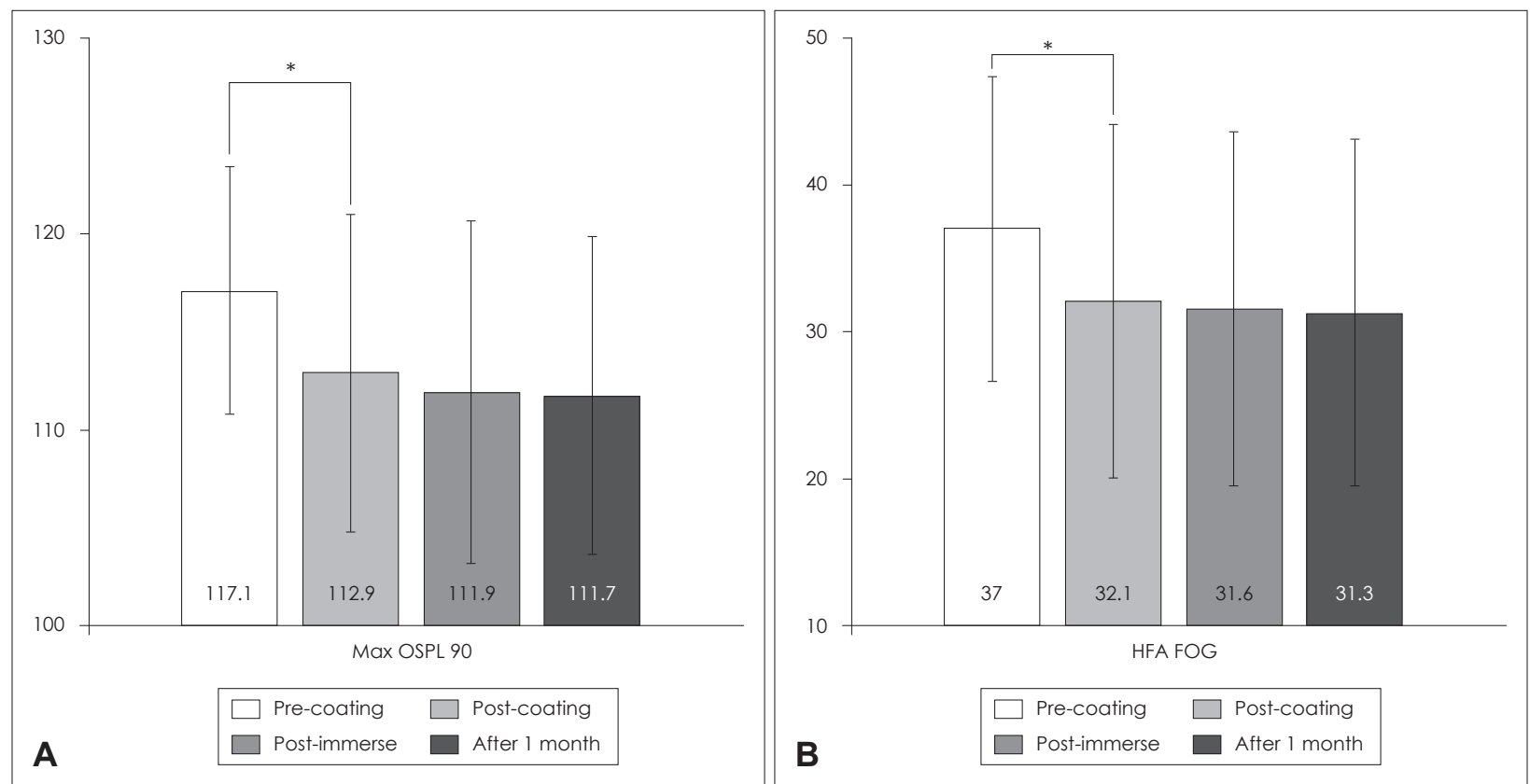

Fig. 4. Max OSPL 90 (A) and HFA FOG (B) of the hearing aids at each conditions. Reduction in the Max OSPL 90, HFA FOG have been observed statistically significant difference between pre-coating group and post-coating group. ${ }^{*} p<0.05$. Max OSPL 90 : maximum output sound pressure level, HFA FOG: high frequency average full on gain.

Table 3. Analysis of performance of hearing aids that apply hydrophobic nano-coating technique

\begin{tabular}{lcccccc}
\hline \multirow{2}{*}{$\begin{array}{c}\text { Coating } \\
\text { groups }\end{array}$} & Max OSPL 90 (dB) & HFA FOG $(\mathrm{dB})$ & \multicolumn{3}{c}{ THD (\%) } & Ln (dB) \\
\cline { 4 - 6 } Pre-coating & $117.1 \pm 6.3$ & $37.0 \pm 10.3$ & $500 \mathrm{~Hz}$ & $800 \mathrm{~Hz}$ & $1600 \mathrm{~Hz}$ & $26.4 \pm 2.0$ \\
Post-coating & $112.9 \pm 8.1^{*}$ & $32.1 \pm 12.0^{*}$ & $1.4 \pm 0.6$ & $1.0 \pm 0.6$ & $1.1 \pm 0.6$ & $27.4 \pm 2.7$ \\
Post-immerse & $111.9 \pm 8.7$ & $31.6 \pm 12.0$ & $1.6 \pm 1.4$ & $0.6 \pm 0.2$ & $0.4 \pm 0.3$ & 0.6 \\
After 1 month & $111.7 \pm 8.1$ & $31.3 \pm 11.8$ & $1.6 \pm 1.3$ & $0.7 \pm 0.3$ & $0.6 \pm 0.4$ & $29.0 \pm 2.8$ \\
\hline
\end{tabular}

* $p<0.05$. Max OSPL 90: maximum output sound pressure level, HFA FOG: high frequency average full on gain, THD: total harmonic distortion, Ln: equivalent input noise level

Table 4. Analysis of performance of hearing aids that didn't apply hydrophobic nano-coating technique

\begin{tabular}{lcccccc}
\hline \multirow{2}{*}{$\begin{array}{c}\text { Non-coating } \\
\text { groups }\end{array}$} & Max OSPL $90(\mathrm{~dB})$ & HFA FOG $(\mathrm{dB})$ & \multicolumn{3}{c}{ THD (\%) } & \multicolumn{2}{c}{$\mathrm{Ln}(\mathrm{dB})$} \\
\cline { 4 - 6 } & & & $500 \mathrm{~Hz}$ & $800 \mathrm{~Hz}$ & $1600 \mathrm{~Hz}$ & \\
\hline Pre-immerse & $108.1 \pm 5.2$ & $30.1 \pm 7.8$ & $1.0 \pm 0.4$ & $0.7 \pm 0.2$ & $0.6 \pm 0.2$ & $25.9 \pm 3.8$ \\
Post-immerse & $108.1 \pm 5.1$ & $30.6 \pm 7.6$ & $0.9 \pm 0.4$ & $0.8 \pm 0.3$ & $0.6 \pm 0.2$ & $26.4 \pm 3.1$ \\
After 1 month & $107.8 \pm 4.2$ & $30.5 \pm 7.8$ & $1.0 \pm 0.5$ & $0.8 \pm 0.2$ & $0.6 \pm 0.1$ & $26.1 \pm 3.4$ \\
\hline
\end{tabular}

Max OSPL 90: maximum output sound pressure level, HFA FOG: high frequency average full on gain, THD: total harmonic distortion, Ln: equivalent input noise level 
로 나타났다(Table 4).

하지만 보청기 회로기판 상태를 평가하기 위해 보청기를 분 해한 결과 나노방수코팅 되지 않은 보청기 회로 기판의 일부에 서 부식이 발생되고 있음을 확인할 수 있었다(Fig. 2E and F).

\section{고 찰}

최근 기술의 발전에 의해 보청기는 형태적인 측면에서 BTE 타입부터 ITC 타입, CIC 타입, RIC 타입까지 다양한 종류가 나와 있고 기능적으로 무선통신기술(Wi-Fi), 블루투스를 이 용하여 스마트폰 및 기타 전자기기와의 원격 연결 및 조절까 지 가능해진 상태이다. ${ }^{5)}$ 하지만 이러한 기술적 발전에도 불 구하고, 아직까지도 땀 및 이물질의 유입에 의한 출력 저하와 잦은 고장은 보청기 착용 환자가 겪는 가장 흔한 문제 중 하 나이다.) 최근 일부 보청기 회사에서 BTE 형의 경우, 모든 먼 지 입자에 대한 방진 및 $1 \mathrm{~m}$ 의 수심에서 30 분 이상 방수효과 를 보이는 IP67등급의 제품이 출시되고 있으나 다른 타입의 보청기의 경우에는 아직 방수 기술을 적용한 제품이 출시되 지 않았다. 본 연구에서 이용한 나노방수코팅은 Yoshimitsu 등ㄱㄱㄱㅘ Feng 등 ${ }^{8)}$ 이 회로기판의 기능을 보존하면서 부식을 방 지하기 위해 제안한 방법으로 핸드폰을 비롯한 전자기기에 소수성 코팅막을 형성하는 발수 코팅법(water-resistant)과 다르게 기상증착공정(Vapor Deposition Process)을 추가로 적용하여 방수력을 높이는(water-proof) 기술로 발전되었 다. ${ }^{9}$ 이 기술은 핀홀(pin-hole)이 없는 균일하고 투명한 보호 막과 같은 불투과성 피막을 전자부품에 증착시켜 부식 및 침 수에 대한 회로의 고장을 방지할 수 있으며, 발수(water-resistant) 수준의 플라즈마(plasma) 또는 스프레이(spray) 코 팅과는 달리 코팅 후 수중에서 기기의 고장 없이 정상적으로 작동 가능하다는 장점이 있기 때문에, 본 저자들은 이 기술 을 보청기에 적용할 수 있을 것으로 판단하였다. ${ }^{10)}$

나노방수코팅을 한 보청기 군에서 코팅 후 보청기 성능을 측정하였을 때 3 개의 $\mathrm{CIC}$ 타입 보청기 중 2 개가 기기 고장으 로 작동되지 않았다. 이는 정확한 원인을 알 수 없었지만 추 정해보면 $\mathrm{CIC}$ 타입은 가장 작은 사이즈의 보청기로 회로기 판 및 각종 부품들이 좁은 공간 내에 최대한 밀집되어 있는 형태이기 때문에 코팅 시 미세한 두께 차이가 발생할 수도 있으며 기상증착공정에서 발생하는 열이 회로 및 부품에 영 향을 미쳤을 가능성도 생각해 볼 수 있다. 하지만 이에 대해 서는 추가적인 연구가 필요할 것으로 생각된다.

그리고 본 연구에서 기준으로 정한 방수 등급 IP67은 현재 방수처리되어 출시된 BTE 타입 보청기와 방수력면에서는 차이를 보이지 않지만 방수처리 기술의 종류가 다르다.
현재 판매되고 있는 방수처리된 BTE 보청기(Aquaris ${ }^{\mathrm{TM}}$, SIEMENS, Munich, Germany)는 배터리 입구 부분을 얇은 고무 재질로 씨우고, 마이크 및 리시버에는 고어텍스(Gore$\mathrm{Tex}$ ) 재질을 장착한 고전적인 기계적 방수 기술(mechanical seal)이 적용되어 있다.

하지만, 이러한 기법은 상대적으로 큰 BTE 보청기에서나 가능하며, 물리적 공간이 작은 ITC, $\mathrm{CIC}$ 형태의 보청기의 경 우 기계적 방수기술을 적용하기가 어려울 수 있다.

하지만 본 저자들이 소개한 나노방수코팅은 마이크, 회로 기판, 리시버가 연결된 상태에서 일괄적 코팅이 가능하기 때문 에, 기존의 기계적 방수 기술이 가지고 있는 한계점을 극복 할 수 있다. 일반 전자기기의 나노방수코팅 두께는 5 8 $\mu \mathrm{m}$ 이 지만 보청기 특성상 출력 및 이득의 영향을 줄 수 있을 것으 로 판단하여 $2.5 \mu \mathrm{m}$ 의 두께로 정하였다. 실험 결과 $2.5 \mu \mathrm{m}$ 의 두께의 코팅은 일부 보청기에서 코팅 전보다 Max OSPL 90, $\mathrm{HFA} \mathrm{FOG}$ 의 차이를 보였지만 침수테스트에서는 성능이 유 지되었다. 보청기 성능 테스트 시 이상 유무를 판단하기 위 한 허용한계치는 Max OSPL 90 의 경우 $\pm 4 \mathrm{~dB}$ 이고, $\mathrm{HFA}$ $\mathrm{FOG}$ 는 $\pm 5 \mathrm{~dB}$ 임을 참고하였을 때 본 연구에서 Max OSPL 90 의 코팅 전후 변화폭은 허용한계치를 벗어났으며 HFA FOG 의 코팅 전후 변화폭은 한계치 경계선상에 있음을 알 수 있 다. ${ }^{11)}$ 또한 1 개월 후 방수지속성을 판단하기 위해 실시한 성 능평가에서 각 평가 인자들의 성능 저하는 관찰되지 않았다. 본 연구에서는 코팅 후 출력이 유의하게 감소된 이유는 제조 된 보청기 회로기판에 방수 코팅을 일괄 적용함으로써 보청 기에서 핵심적인 역할을 하는 마이크, 리시버, 앰프와 같은 부품들이 코팅되었기 때문으로 판단된다. 이를 해결하기 위해 서는 보청기 제조단계에서의 부품별 방수처리 과정을 진행하 여 각 부속품의 코팅 두께를 다르게 함으로써 방수처리 후 성능 저하가 일어나지 않는 각각의 코팅 두께를 연구해야 할 것이다. 또한 전자기기에 적용되고 있는 여러 방수 코팅 방법 을 비교하여 코팅의 종류 및 침수 용액의 성상을 다양하게 적용하여 비교함으로써 보청기에 가장 적합한 방수 코팅 방 법을 찾아내야 할 것이다. 그리고 침수 후 상태를 장기간 추 적하면서 회로 기판의 부식이 성능 저하 및 보청기 고장을 일으키는지 관찰할 필요가 있다. 이러한 비교연구 후 다양한 타입의 보청기를 방수 코팅 처리하여 직접 환자에게 착용시 켜 보고 사용 후 설문조사 및 보청기 성능 테스트를 시행하 여 만족스러운 결과를 얻는다면, 난청 환자들의 사회 활동 정도 및 야외 활동 정도, 나아가 삶의 질이 향상되고 한 단계 높은 재활 환경을 제공할 수 있을 것으로 판단된다. ${ }^{12)}$

나노방수코팅을 시행하지 않았던 보청기 군에서 침수 실험 을 시행하였을 때 침수 24 시간 후와 1 개월 후 측정한 보청기 
성능 평가에서는 통계적으로 유의한 차이가 없음을 알 수 있 었다. 하지만 1 개월 후 회로 기판을 관찰해 본 결과 일부분이 부식된 것을 확인하였다. 침수 및 이물질 유입으로 인한 전자 기기의 회로기판 부식은 이물질의 양, 온도, 전해질 함량, 유 입 속도, 회로 기판의 재질, 기후에 따라 시작 시점이 다르 다. ${ }^{13)}$ 모든 부식은 가속화되는 경향을 보이며 회로 기판의 부 식은 기기의 고장과 밀접한 연관이 있기 때문에 ${ }^{14)}$ 본 연구기 간 보다 긴 시간 동안 추적관찰 해 본다면 기기의 고장 시점을 알 수 있을 것이다.

\section{REFERENCES}

1) Lybarger SF, Lybarger EH. A historical overview. In: Sandlin R, editor. Textbook of hearing aid amplification: Technical and clinical considerations. 2nd ed. San Diego, CA: Singular Thomson Learning; 2000. p.1-35

2) Metselaar M, Maat B, Verschuure H, Dreschler WA, Feenstra L. Comparative studies on hearing aid selection and fitting procedures: a review of the literature. Eur Arch Otorhinolaryngol 2008;265(1): 21-9.

3) Chang YS, Choi J, Park GY, Youm HY, Byun HY, Cho YS. Evaluation of satisfaction with hearing aids using a questionnaire based on MarkeTrak survey. Korean J Otorhinolaryngol-Head Neck Surg 2014;57(5):304-13.

4) IS/IEC 60529. Degrees of protection provided by enclosures (IP CODE), Ed. 2.1. International Electrotechnical Commision;2011.

5) Kim JS, Kim $\mathrm{CH}$. A review of assistive listening device and digital wireless technology for hearing instruments. Korean J Audiol 2014; 18(3):105-11.

6) Bertoli S, Staehelin K, Zemp E, Schindler C, Bodmer D, Probst R. Survey on hearing aid use and satisfaction in Switzerland and their determinants. Int J Audiol 2009;48(4):183-95.

7) Yoshimitsu Z, Nakajima A, Watanabe T, Hashimoto K. Effects of surface structure on the hydrophobicity and sliding behavior of water droplets. Langmuir 2002;18(15):5818-22.

8) Feng L, Li S, Li Y, Li H, Zhang L, Zhai J, et al. Super-hydrophobic surfaces: from natural to artificial. Adv Mater 2002:14(24):1857-60.

9) Chang KC, Ji WF, Lai MC, Hsiao YR, Hsu CH, Chuang TL, et al. Synergistic effects of hydrophobicity and gas barrier properties on the anticorrosion property of PMMA nanocomposite coatings embedded with graphene nanosheets. Polym Chem 2014;5(3):1049-56.

10) Xie J, Mao H, Yu DG, Williams GR, Jin M. Highly stable coated polyvinylpyrrolidone nanofibers prepared using modified coaxial electrospinning. Fibers Polym 2014:15(1):78-83.

11) ANSI S3.22-2003. Specification of hearing aid characteristics. New York: American National Standards Institute;2003.

12) Chisolm TH, Johnson CE, Danhauer JL, Portz LJ, Abrams HB, Lesner S, et al. A systematic review of health-related quality of life and hearing aids: final report of the American Academy of Audiology Task Force On the Health-Related Quality of Life Benefits of Amplification in Adults. J Am Acad Audiol 2007;18(2):151-83.

13) Veleva L, Valdez B, Lopez G, Vargas L, Flores J. Atmospheric corrosion of electro-electronics metals in urban desert simulated indoor environment. Corros Eng Sci Technol 2008;43(2):149-55.

14) Lopez BG, Valdez SB, Zlatev KR, Flores PJ, Carrillo BM, Schorr WM. Corrosion of metals at indoor conditions in the electronics manufacturing industry. Anticorros Methods Mater 2007;54(6): $354-9$. 